\title{
Fabrication of Sb-doped p-type ZnO Thin Films by Pulsed Laser Deposition
}

\author{
Yu-Feng Hsiou", Wei-Kuan Hung", and Chiu-Wei Wang \\ Department of Electro-Optical Engineering, National Taipei University of Technology, Taipei 10608, Taiwan.
}

Received: June 16, 2015 / Accepted: June 28, 2015

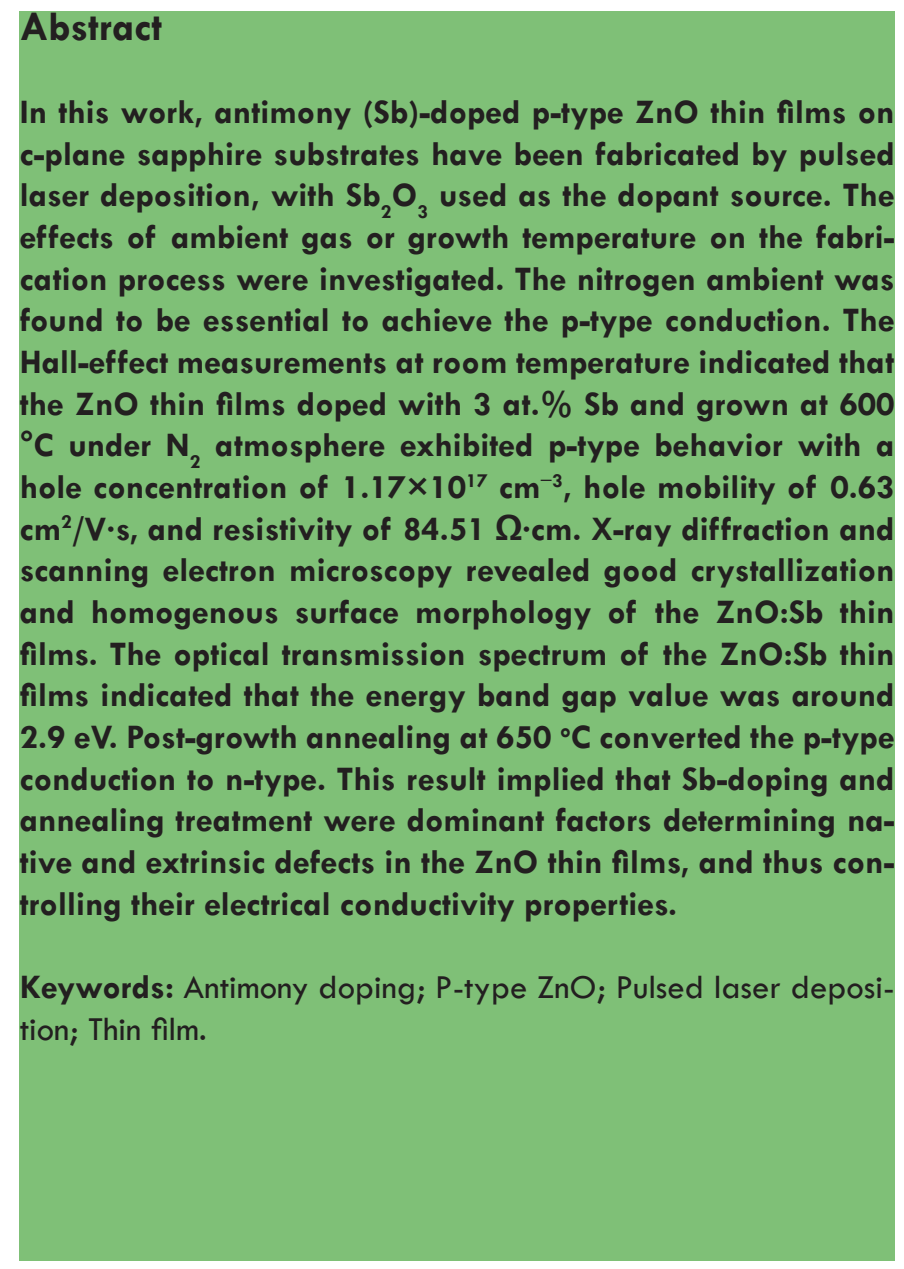

*Corresponding authors: yfhsiou@ntu.edu.tw; wkhung@ntut. edu.tw

\section{Introduction}

Zinc Oxide $(\mathrm{ZnO})$ has been considered as one of the most promising materials for optoelectronic applications due to its wide energy band gap of $3.37 \mathrm{eV}$, large exciton binding energy of $60 \mathrm{meV}$, high optical gain, high radiation and temperature stability (Klingshirn, 1975; Pandey et al., 2013). In order to develop the $\mathrm{ZnO}$-based optoelectronic devices, the first step is the fabrication process of high-quality $\mathrm{n}$ - or $\mathrm{p}$ - type $\mathrm{ZnO}$ thin films. It is easy to grow good-quality n-type $\mathrm{ZnO}$ with resistivity of 1-2 orders of magnitude higher than metals, because of intrinsic non-stoichiometric growth of $\mathrm{ZnO}$ (Yamamoto et al., 2001). However, one of the current challenges in the fabrication process is to prepare p-type $\mathrm{ZnO}$. The p-type conduction has been realized by doping with elements of N (Guo et al., 2003), As (Look et al., 2004), P (Kim et al., 2003), Li (Zeng et al., 2006), Li/N co-doping (Zhang et al., 2010), and so on. However, indistinct doping mechanism and reliable p-type conduction are still the essential issues that hinder the development of all $\mathrm{ZnO}$-based optoelectronic devices. A model has been proposed for group- $V$ dopants, such as $\mathrm{As}$ and Sb, to achieve reliable p-type conduction in $\mathrm{ZnO}$ (Limpijumnong et al., 2004). In this model, a Sb $\mathrm{zn}_{\mathrm{z}}-2 \mathrm{~V}_{\mathrm{Zn}}$ complex was considered to primarily cause the acceptor-like behavior in the Sb-doped $\mathrm{ZnO}$ (SZO) films (Limpijumnong et al., 2004). According to their theory, the Sb atom occupying Zn side $\left(\mathrm{Sb}_{\mathrm{Zn}}\right)$ in $\mathrm{ZnO}$ has sufficient energy to spontaneously induce two zinc vacancies $\left(\mathrm{V}_{\mathrm{zn}}\right)$, forming a shallow acceptor complex $\left(\mathrm{Sb}_{\mathrm{Zn}}\right.$ $\left.2 V_{z n}\right)$ with a formation energy $\left(\Delta H_{f}\right)$ of $2.0 \mathrm{eV}$ and an acceptor ionization energy of $0.16 \mathrm{eV}$. In addition, controversial results on oxygen-rich growth condition or annealing processes have been reported for achieving p-type conductivity in this system.

SZO films have been grown by various deposition techniques,
ATLOS Publishing, LP
This is an Open Access article distributed under the terms of the Creative Commons Attribution License (http://creativecommons.org/licenses/by/3.0/), which permits unrestricted use, distribution, and reproduction in any medium, provided the original work is properly cited. 
such as molecular beam epitaxy (Xiu et al., 2005), pulsed laser deposition (PLD) (Guo et al., 2007), radio-frequency sputtering (Wanga et al., 2006), and dual ion beam sputtering deposition (Pandey et al., 2013). However, the prepared p-type $\mathrm{ZnO}$ thin films exhibited diverse characteristics and properties with poor stabilities. In this work, we study the p-type behavior in Sbdoped $\mathrm{ZnO}$ thin films fabricated by PLD. The effects of ambient and growth temperature are investigated for further exploration.

\section{Materials and Methods}

The $\mathrm{ZnO}: \mathrm{Sb}$ films were deposited on c-plane sapphire substrates by PLD. The targets were high-purity $\mathrm{ZnO}-\mathrm{Sb}_{2} \mathrm{O}_{3}$ ceramic disks with various Sb contents. The Nd:YAG Q-switched laser with $266 \mathrm{~nm}$ wavelength and a pulsed duration less than $10 \mathrm{~ns}$ was adopted as the ablation source. The sapphire substrates were rinsed thoroughly with acetone, alcohol, and de-ionized water; and were subsequently purged by pure nitrogen gas in order to remove dust particles and various organic contaminants before being loaded into the chamber. The sapphire substrates were baked at $600{ }^{\circ} \mathrm{C}$ for $40 \mathrm{~min}$ in vacuum inside the deposition chamber before the growth process.

The vacuum chamber was pumped to a base pressure of $3 \times 10^{-6}$ torr. The growth temperature varied from 450 to 650 ${ }^{\circ} \mathrm{C}$. Oxygen, nitrogen, and argon were used as the ambient gases at the flow rate of $5 \mathrm{sccm}$ (standard cubic centimeters per minute). The working pressure was kept at $1 \times 10^{-2}$ torr during the growth process. The laser repetition rate was $10 \mathrm{~Hz}$ and the energy per pulse was $1.5 \mathrm{~J} / \mathrm{cm}^{2}$. All the films were deposited for duration of 12,000 laser pulses in this work.

\section{Results and Discussion}

The average thickness of the Sb-doped $\mathrm{ZnO}$ thin films was approximately $200 \mathrm{~nm}$, as measured by cross-sectional scanning electron microscopy (SEM). Room-temperature Hall effect measurements were carried out using van der Pauw configuration. The $\mathrm{ZnO}-\mathrm{Sb}_{2} \mathrm{O}_{3}$ targets with Sb contents of 1, 3, 5, and 7 at. $\%$ were used to make sure the suitable atomic weight percentage of $\mathrm{Sb}$.

Fig. 1 shows X-ray diffraction (XRD) patterns of the Sbdoped $\mathrm{ZnO}$ films grown with different atomic weight percentage of antimony. Only one peak corresponding to $\mathrm{ZnO}$ (002) plane is observed because that all the fabricated films were at (002) highly preferential orientation, while no any other secondary phases, such as $\mathrm{Sb}_{2} \mathrm{O}_{3}$, are detected in the patterns. The angle position of the $(002)$ peak shifts evidently with the target $\mathrm{Sb}$ content, indicating the incorporation of $\mathrm{Sb}$ into the $\mathrm{ZnO}$ lattice. The incorporation of $\mathrm{Sb}$ into the $\mathrm{ZnO}$ host lattice leads to the change in the lattice constant, which in turn leads to the diffraction angle shift, according to the Bragg's law.

Table 1 summarizes the electrical properties of $\mathrm{Sb}$ doped $\mathrm{ZnO}$ thin films grown with targets composed of $\mathrm{Sb}$ in different atomic weight percentages. The insulating sapphire substrates as adopted here can assure that any conduction type must come from the $\mathrm{ZnO}$ films rather than from the substrates. It seems that

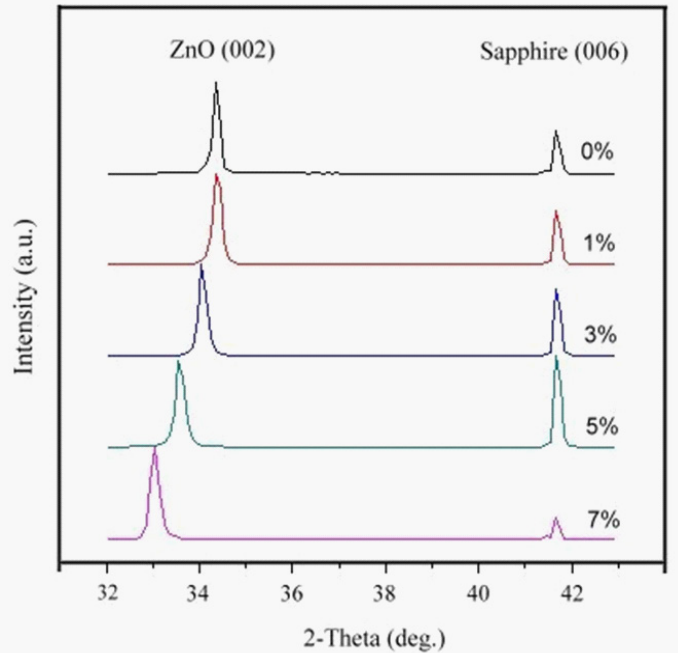

Fig. 1. X-ray diffraction patterns of Sb-doped $\mathrm{ZnO}$ thin films grown with different $\mathrm{Sb}$ at \%. The angle of $\mathrm{ZnO}$ (002) peak shifts to lower angles as $\mathrm{Sb}$ at \% increases.

Table 1. Electrical properties of Sb-doped $\mathrm{ZnO}$ thin films grown by using targets with different $\mathrm{Sb}$ at \%.

\begin{tabular}{lllll}
\hline Sb at \% & $\begin{array}{l}\text { Resistivity } \\
(\boldsymbol{\Omega}-\mathbf{c m})\end{array}$ & $\begin{array}{l}\text { Hall mobility } \\
\left(\mathbf{c m}^{\mathbf{2}} \mathbf{V} \cdot \mathbf{s}\right)\end{array}$ & $\begin{array}{l}\text { Carrier Conc. } \\
\left(\mathbf{c m}^{-3}\right)\end{array}$ & $\begin{array}{l}\text { Conduction } \\
\text { Type }\end{array}$ \\
\hline $0 \%$ & 0.5 & 40.7 & $3.08 \times 10^{17}$ & $\mathrm{n}$ \\
$1 \%$ & 1968 & 71.97 & $4.41 \times 10^{13}$ & $\mathrm{n}$ \\
$3 \%$ & $>1 \mathrm{G} \Omega$ & --- & --- & --- \\
$5 \%$ & $>1 G \Omega$ & --- & --- & --- \\
$7 \%$ & $>1 G \Omega$ & --- & --- & --- \\
\hline
\end{tabular}

p-type conduction cannot be achieved in the range of 1-7 at \%.

The film grown with 1 at \% Sb presents a n-type conduction. This is probably associated with the formation of oxygen vacancy because the Sb-related acceptor is not enough to compensate the background electrons from the native defects. When the atomic weight percentage of antimony is higher than 3 at. $\%$, the sample shows relatively high resistivity (the resistance is higher than 1 Giga Ohms), which may be caused by the reduction of hole concentration that is due to the formation of native defects at high oxygen working pressure, according to Samanta's research (Samanta et al., 2012). These native defects normally give n-type background carriers and act as a trap for non-equilibrium holes in the $\mathrm{ZnO}: \mathrm{Sb}$ thin film. Thus, the doped $\mathrm{Sb}$ atom cannot create strong discrepancy of conduction type. It seems better to choose the $3 \%$ target as the starting point, based on the observation that the electron concentration decreases with increasing Sb content. In order to achieve the p-type doping, it needs to adjust growth parameters, such as ambient and temperature, to compensate the intrinsic n-type doping.

The $\mathrm{ZnO}-\mathrm{Sb}_{2} \mathrm{O}_{3}$ target with Sb content of 3 at. $\%$ was used to grow p-type $\mathrm{ZnO}: \mathrm{Sb}$ thin films under the ambient oxygen, nitrogen, or argon gases, respectively, according to Table 2 . The other growth parameters were held the same as described above. The electrical properties of three samples are summarized in Table 2. It seems that p-type conduction can be achieved in either nitrogen or argon ambient gases. However, the hole concentration in the sample produced in nitrogen is $1.17 \times 10^{17} \mathrm{~cm}^{-3}$, which is much higher than the one grown in argon atmosphere. 
Table 2. Electrical properties of $3 a t \% \mathrm{Sb}$-doped $\mathrm{ZnO}$ thin films grown in different ambient gases.

\begin{tabular}{lllll}
\hline Ambient Gas & $\begin{array}{l}\text { Resistivity } \\
(\Omega \cdot \mathrm{cm})\end{array}$ & $\begin{array}{l}\text { Hall Mobility } \\
\left(\mathrm{cm}^{2} / \mathbf{V} \cdot \mathbf{s}\right)\end{array}$ & $\begin{array}{l}\text { Carrier Conc. } \\
\left(\mathrm{cm}^{-3}\right)\end{array}$ & $\begin{array}{l}\text { Conduction } \\
\text { Type }\end{array}$ \\
\hline $5 \mathrm{sccm} \mathrm{O}_{2}$ & $>1 G \Omega$ & $\cdots$ & $\cdots$ & $-\cdots$ \\
$5 \mathrm{sccm} \mathrm{N} N_{2}$ & 84.51 & 0.63 & $1.17 \times 10^{17}$ & $P$ \\
$5 \mathrm{sccm} \mathrm{Ar}$ & 273.45 & 18.28 & $1.25 \times 10^{15}$ & $\mathrm{P}$ \\
\hline
\end{tabular}

The reason may be that the p-type conduction has been realized by doping nitrogen atom, and therefore it is a reasonable assumption that the nitrogen gas helps to increase the hole concentration. In addition, there is no publication on adopting Ar as ambient gas in $\mathrm{ZnO}: \mathrm{Sb}$ thin film, whereas there are many papers evaluated the $\mathrm{Ar}$ as ambient gas for $\mathrm{ZnO}$ thin film (Igasaki et al., 2004; Park et al., 2007.) Apparently, Ar ambient gas affects the characteristic of $\mathrm{ZnO}$ thin film and the correlated features of $\mathrm{Sb}$-doped $\mathrm{ZnO}$ thin films. The p-type conduction can be reasonably achieved in Ar ambient gas.

Fig. 2 shows XRD patterns of the Sb-doped $\mathrm{ZnO}$ films grown in different ambient gases. Only one diffraction peak corresponding to $\mathrm{ZnO}(002)$ plane is observed, and no secondary phase is detected. It is suggested that all the films are at (002) high preferential orientation. The full width half maximum (FWHM) of the (002) diffraction peak is $0.195^{\circ}, 0.21^{\circ}$, and $0.29^{\circ}$ for the samples grown in the $\mathrm{N}_{2}, \mathrm{O}_{2}$, and Ar ambient gases, respectively, suggesting that the crystallinity of the sample grown in ambient nitrogen gas is superior to others. The same XRD angle as depicted in Fig. 2 implies the same amount of Sb atoms doped into the $\mathrm{ZnO}$ thin films. Nevertheless, the thin film deposited in the $\mathrm{N}_{2}$ atmosphere reaches higher hole concentration under same amount of doped $\mathrm{Sb}$ atoms, according to Table 2.

In an attempt to reduce the high resistivity and to crystallize the grown film, an in-situ post-growth annealing was processed at $650^{\circ} \mathrm{C}$ for $30 \mathrm{~min}$. Under this condition, the resistivity is com-

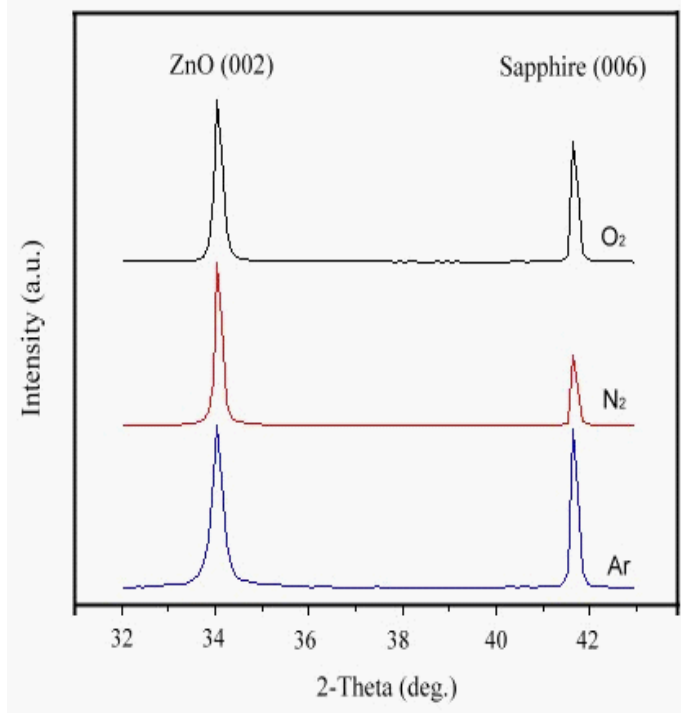

Fig. 2. X-ray diffraction patterns of Sb-doped $\mathrm{ZnO}$ thin films grown in different ambient gases. The $\mathrm{ZnO}$ (002) peak angle remains the same angle position without any shift. paratively low, however, the conduction type converts back to ntype. This was probably associated with the Sb-related acceptor being not enough to compensate the background electrons from the native defects. Increasing of native donors results in a decrease of hole concentration via electron-hole recombination (Samanta et al, 2012). It is easy to observe the specific phenomenon at a high temperature growth. However, better understanding of this origin is in progress.

To optimize the electrical properties and crystallization of the $\mathrm{Sb}$-doped p-type $\mathrm{ZnO}$ thin films in ambient nitrogen gas, a highpurity $\mathrm{ZnO}-\mathrm{Sb}_{2} \mathrm{O}_{3}$ ceramic disk with $\mathrm{Sb}$ content of 3 at.\% was used as the target and nitrogen gas was applied for the ambient gas. The growth temperature varied from 450 to $650{ }^{\circ} \mathrm{C}$. Fig. 3 shows XRD patterns of the Sb-doped $\mathrm{ZnO}$ films grown at different temperatures. Only one diffraction peak corresponding to $\mathrm{ZnO}(002)$ plane is observed, and no secondary phase is detected in this patterns. It suggests that all the films are highly (002) oriented. The FWHM of the (002) peak decreases evidently as the temperature increases, indicating that the crystallinity is improved at a high growth temperature. However, the conduction type is n-type at $450{ }^{\circ} \mathrm{C}$ and $650^{\circ} \mathrm{C}$. The growth temperature of $600{ }^{\circ} \mathrm{C}$ is one of the dominant parameters in this study. The provided energy may be insufficient if the growth temperature set at $450{ }^{\circ} \mathrm{C}$ is not high enough. Therefore, the amount of active donors is less, in spite of the fact that doping more Sb atoms into $\mathrm{ZnO}$ might cause strong deformation of the original lattice. The native defect behavior at the same growth temperature may be similar while annealing temperature is set at $650{ }^{\circ} \mathrm{C}$. Therefore, when the growth temperature remains at $650{ }^{\circ} \mathrm{C}$, the hole concentration is reduced due to the increase of native donors. A decrease of hole concentration via electron-hole recombination is thus sustained (Samanta et al., 2012). Therefore, it is reasonable that the conduction type remains in n-type due to the increased native donors of $\mathrm{ZnO}: \mathrm{Sb}$ thin film at $650{ }^{\circ} \mathrm{C}$ growth temperature

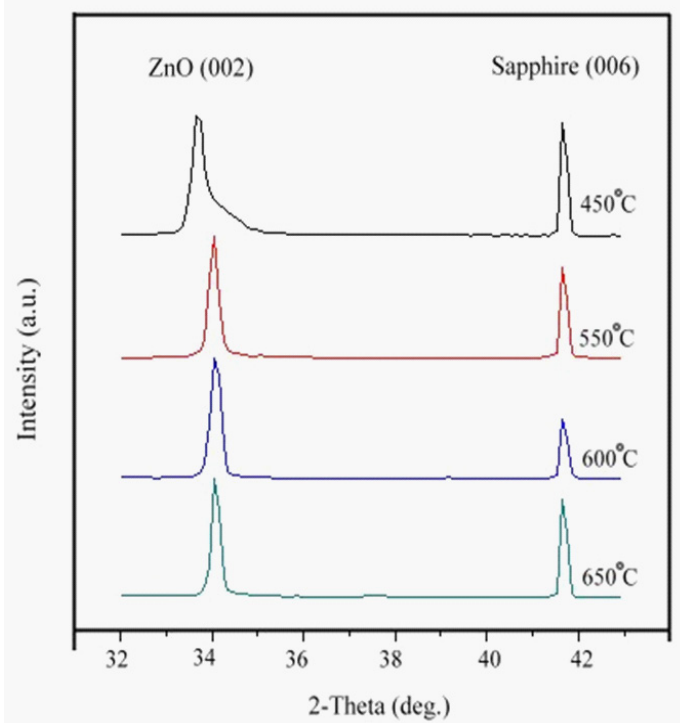

Fig. 3. X-ray diffraction patterns of Sb-doped $\mathrm{ZnO}$ thin films grown at different temperatures. The p-type behavior of $\mathrm{Sb}$-doped $\mathrm{ZnO}$ thin films was observed at 550 ${ }^{\circ} \mathrm{C}$ and $600{ }^{\circ} \mathrm{C}$; however, the $\mathrm{Sb}$-doped $\mathrm{ZnO}$ exhibited n-type behavior at $450^{\circ} \mathrm{C}$ and $650^{\circ} \mathrm{C}$. 
as presented in this work. Further investigations of SZO homojunction with similar growth condition despite the growth temperature is suggested in the future.

The surface morphology of the $\mathrm{Sb}$-doped $\mathrm{ZnO}$ thin film grown at $600{ }^{\circ} \mathrm{C}$ was observed by SEM. As shown in Fig. 4, the surface is composed of dense grains with a similar size, which is consistent with the XRD result. This result suggested that the Sb-doped $\mathrm{ZnO}$ films seemed to reach acceptable crystallinity.

The optical transmission spectrum of the $\mathrm{ZnO}: \mathrm{Sb}$ thin film is shown in Fig. 5. The value of transmittance of thin films in the visible range is about $65-85 \%$, which rises with increasing wavelength while becomes fixed near the UV band. The value of band gap is estimated from fundamental absorption edge of the films. For the direct transitions, the absorption coefficient is expressed as follows:

$$
\alpha^{2}(h v)=A\left(h v-E_{g}\right)
$$

where $\mathrm{A}$ is the constant, $\mathrm{E}_{\mathrm{g}}$ is the energy gap, $v$ is the frequency of the incident radiation and $h$ is Planck's constant.

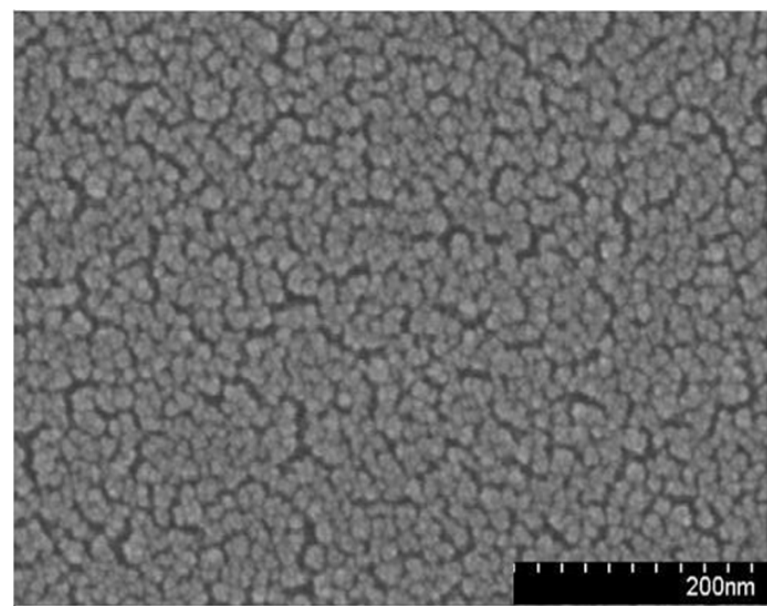

Fig. 4. SEM morphology of Sb-doped $\mathrm{ZnO}$ thin film grown at $600^{\circ} \mathrm{C}$.

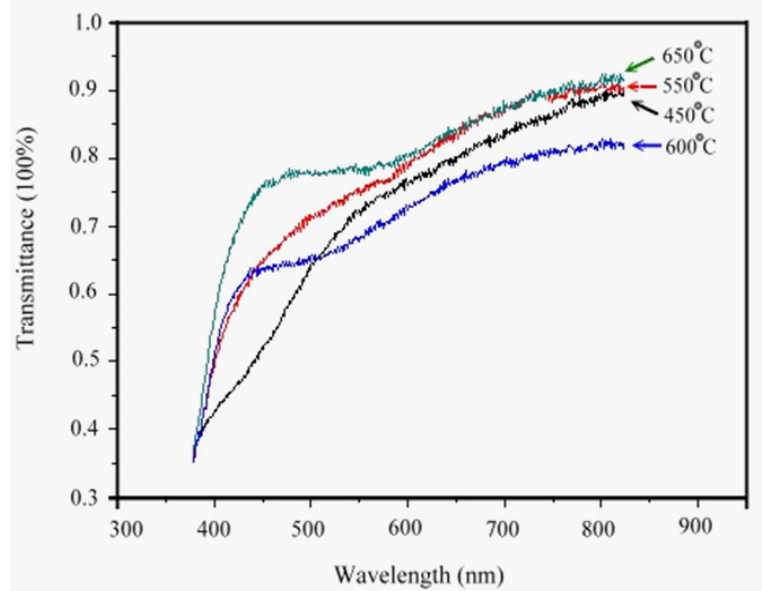

Fig. 5. Transmission spectra of $\mathrm{ZnO}: \mathrm{Sb}$ thin films at different growth temperatures. The transmittance rises as the wavelength increases, while the are almost the same near the UV range.

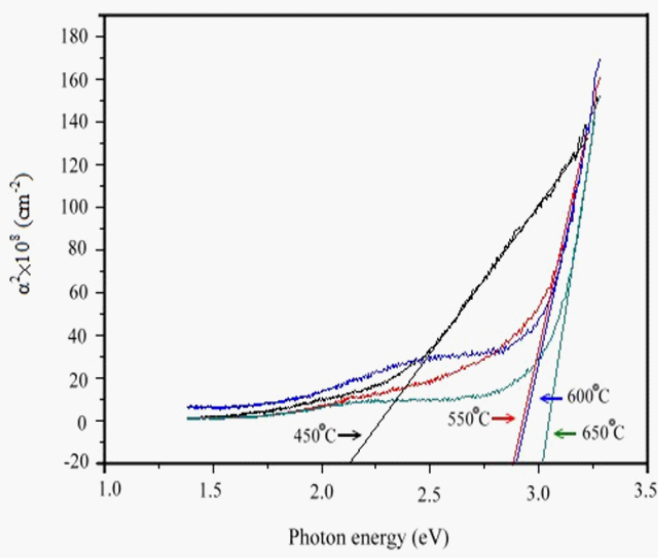

Fig. 6. Plot of $\alpha^{2}$ vs. $h v$ for the $\mathrm{ZnO}: \mathrm{Sb}$ thin films at different temperatures. The band gap values are almost the same at $550^{\circ} \mathrm{C}$ and $600{ }^{\circ} \mathrm{C}$, while it is less at 650 ${ }^{\circ} \mathrm{C}$. There exists an extra low band gap value below growth temperature $450^{\circ} \mathrm{C}$.

Fig. 6 shows the plot $\alpha^{2}$ vs. $h v$ for the $\mathrm{ZnO}: \mathrm{Sb}$ thin films. The band gap value of each thin film is calculated from this plot. The X-interceptions are 2.26, 2.90, 2.91, $3.02 \mathrm{eV}$ for 450, 550, $600,650{ }^{\circ} \mathrm{C}$, respectively. The presence of a single slope in the plot suggests that the films have direct and allowed transition. The band gap energy is obtained by extrapolating the regressed straight line to the zero absorption coefficient. The band gap value (photon, eV) of $\mathrm{ZnO}: \mathrm{Sb}$ thin film is found to be around $3 \mathrm{eV}$ except at $450^{\circ} \mathrm{C}$ growth temperature. The band gap value at growth temperature $550{ }^{\circ} \mathrm{C}$ is similar to that at $600{ }^{\circ} \mathrm{C}$, but is $\sim 0.1 \mathrm{eV}$ less than that at $650{ }^{\circ} \mathrm{C}$ which may be due to the acceptor levels of thin films. The band gap is just around 2.25 $\mathrm{eV}$ at $450^{\circ} \mathrm{C}$ growth temperature, due to the impurity level that may result from the defects.

\section{Conclusions}

In summary, $\mathrm{Sb}$-doped $\mathrm{p}$-type $\mathrm{ZnO}$ thin films have been grown on c-plane sapphire substrates by using pulsed laser deposition method. The optimal p-type conduction was achieved at the growth temperature of $600{ }^{\circ} \mathrm{C}$, resulting a resistivity of 84.51 $\Omega \cdot \mathrm{cm}$, carrier concentration of $1.17 \times 10^{17} \mathrm{~cm}^{-3}$ and Hall mobility of $0.63 \mathrm{~cm}^{2} / \mathrm{V} \cdot \mathrm{s}$. No p-type conduction was found in Sb-doped $\mathrm{ZnO}$ films upon post-growth annealing treatment. Furthermore, the incorporation of $\mathrm{Sb}$ into the $\mathrm{ZnO}$ thin films was identified and confirmed by XRD analysis. SEM image and XRD pattern showed that the Sb-doped $\mathrm{ZnO}$ films seemed to have acceptable crystallinity. The optical transmission spectrum of the $\mathrm{ZnO}: \mathrm{Sb}$ thin film indicated that the band gap value was around $2.9 \mathrm{eV}$.

\section{References}

Guo W, A Allenic, Y. B. Chen, X. Q. Pan, Y. Che, Y. Che, Z. D. Hu, and B. Liu (2007) Microstructure and properties of epitaxial antimonydoped -type $\mathrm{ZnO}$ films fabricated by pulsed laser deposition. Appl. Phys. Lett. 90: 242108.

Guo XL, H. Tabata, and T. Kawai (2001) Pulsed laser reactive deposi- 
tion of p-type $\mathrm{ZnO}$ film enhanced by an electron cyclotron resonance source. J. Cryst. Growth 223: 135-139.

Igasaki $\mathrm{Y}$ and $\mathrm{H}$. Kanma (2001) Transparent conducting $\mathrm{ZnO}$ :Al films deposited on glass substrates. Appl. Sur. Sci. 169-170: 508-51 1.

Kim KK, H. S. Kim, D. K. Hwang, J. H. Lim, and S. J. Park (2003) Realization of p-type $\mathrm{ZnO}$ thin films via phosphorus doping and thermal activation of the dopant. Appl. Phys. Lett. 83: 63-65.

Klingshirn $\mathrm{C}$ (1975) The luminescence of $\mathrm{ZnO}$ under high one- and twoquantum excitation. Physica Status Solidi B: Basic Solid State Physics 71: 547-556.

Limpijumnong S, S. B. Zhang, S. H. Wei, and C. H. Park (2004) Doping by large-Size-Mismatched Impurities: The Microscopic Origin of Arsenic- or Antimony-Doped p-Type Zinc Oxide. Phys. Rev. Lett.92: 155504.

Look DC, G. M. Renlund, R. H. Burgener, and J. R. Sizelove (2004) AsDoped p-Type $\mathrm{ZnO}$ Produced by an Evaporation/Sputtering Process. Appl. Phys. Lett. 85: 5269-5271.

Mukherjee S (2013) Effect of growth temperature on structural, electrical and optical properties of dual ion beam sputtered $\mathrm{ZnO}$ thin films. J. Mater. Sci. Mater. Electron. 24: 2541-2547.

Pandey SK, S. K. Pandey, C. Mukherjee, P. Mishra, M. Gupta, S. R. Barman, S. W. D'Souza, and S. Mukherjee (2013) Effect of growth temperature on structural, electrical and optical properties of dual ion beam sputtered $\mathrm{ZnO}$ thin films. J. Mater. Sci. Mater. Electron. 24(7):
2541-2547.

Park DJ , J.Y. Lee, T. E. Park, Y. Y. Kim, and H. K. Cho (2007) Improved microstructural properties of a $\mathrm{ZnO}$ thin film using a buffer layer insitu annealed in argon ambient. Thin Solid Films. 515: 6721-6725.

Samanta K, A. K. Arora a, S. Hussain b, S. Chakravarty, and R. S. Katiyar (2012) Effect of oxygen partial pressure and annealing on nanocrystalline p-type $\mathrm{ZnO}: \mathrm{Sb}$ thin films. Curr. Appl. Phys. 12: $11381-1385$.

Wanga P, N. Chena, Z. Yina, F. Yanga, and C. Penga (2006) Fabrication and properties of $\mathrm{Sb}$ doped $\mathrm{ZnO}$ thin films growth by radio frequency (RF) magnetron sputtering. J. Cryst. Growth 290: 56-60.

Xiu FX, Z. Yang, L. J. Mandalapu, D. T. Zhao, J. L. Liv, and W. P. Beyermann (2005) High-mobility Sb doped -type $\mathrm{ZnO}$ by molecularbeam epitaxy. Appl. Phys. Lett. 87: 152101.

Yamamoto T, HK Yoshida(2001). Physics and control of valence statesin $\mathrm{ZnO}$ by codoping method. Physica B: Condensed Matter 302-303: 155-162.

Zeng YJ, Z. Z. Ye, W. Z. Xu, D. Y. Li, J. G. Lu, L. P. Zhu, and B. H. Zhao (2006) Dopant source choice for formation of -type $\mathrm{ZnO}$ : Li acceptor. Appl. Phys. Lett. 88: 062107.

Zhang BY, , B. Yao, Y. F. Li, Z. Z. Zhang, B. H. Li, C. X. Shan, D. X. Zhao, and D. Z. Shen (2010) Investigation on the formation mechanism of p-type Li-N dual-doped ZnO. Appl. Phys. Lett. 97: 222101. 